Document downloaded from:

http://hdl.handle.net/10251/121265

This paper must be cited as:

Marques, M.; Agostinho, C.; Zacharewicz, G.; Poler, R.; Jardim-Goncalves, R. (2018). Responsive Production in Manufacturing: A Modular Architecture. Studies in Systems, Decision and Control. 140:231-254. https://doi.org/10.1007/978-3-319-78437-3_10

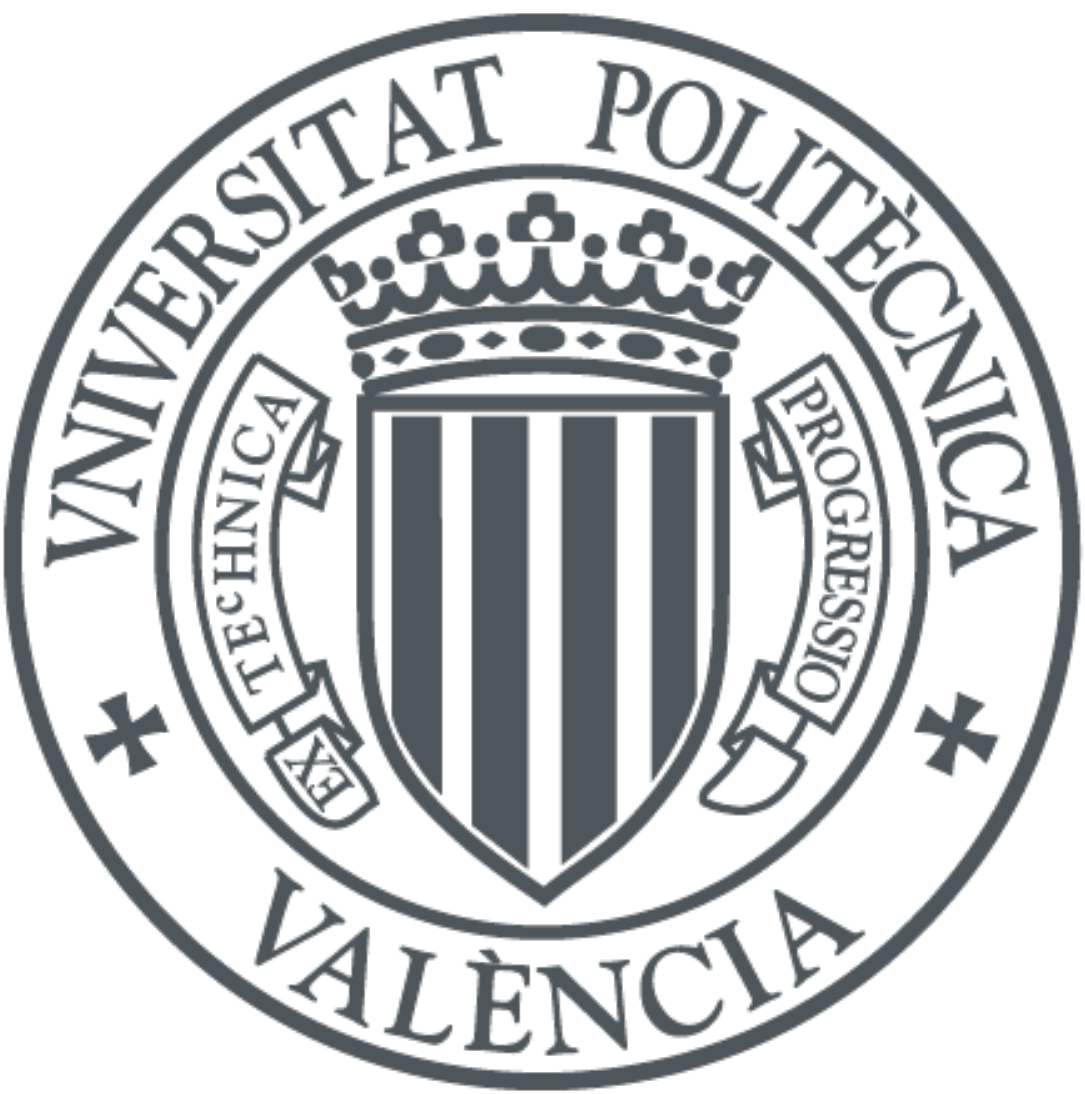

The final publication is available at

https://doi.org/10.1007/978-3-319-78437-3_10

Copyright Springer

Additional Information 


\title{
Responsive Production in Manufacturing: A Modular Architecture
}

\author{
Maria Marques ${ }^{1}$, Carlos Agostinho ${ }^{1}$, Gregory Zacharewicz ${ }^{2}$, Raul Poler ${ }^{3}$ and Ricardo Jardim- \\ Goncalves $^{4}$ \\ 1 Center of Technology and Systems, CTS, UNINOVA 2829-516 Caparica, Portugal \\ 2 University Bordeaux, CNRS, UMR 5218, IMS, F 33405 Talence Cedex, France \\ 3 Research Centre on Production Management and Engineering (CIGIP), Universitat Politècnica de \\ València, Valencia, Spain \\ 4 DEE/FCT, Universidade Nova de Lisboa, 2829-516 Caparica, Portugal
}

\begin{abstract}
This paper proposes an architecture aiming at promoting the convergence of the physical and digital worlds, through CPS and IoT technologies, to accommodate more customized and higher quality products following Industry 4.0 concepts. The architecture combines concepts such as cyber-physical systems, decentralization, modularity and scalability aiming at responsive production. Combining these aspects with virtualization, contextualization, modeling and simulation capabilities it will enable self-adaptation, situational awareness and decentralized decision-making to answer dynamic market demands and support the design and reconfiguration of the manufacturing enterprise.
\end{abstract}

Keywords: Modular production architectures - Cyber-physical systems Internet of Things - Virtualization . Contextualization

\section{Introduction}

Manufacturing represents $16 \%$ of the EU GDP employing more than 30 million persons and the objective of revitalization of the EU economy calls for the endorsement of the reindustrialization efforts to raise the contribution of industry to GDP to as much as $20 \%$ by 2020 [1]. Yet, nowadays, manufacturing companies are facing one of the most challenging moments in their existence, i.e. to cope with the increasingly stricter requirements in terms of flexibility while maintaining their production capacity. The advances in digital automation can contribute significantly to help unleashing their potential to respond to these challenges [2]. Indeed, the explosion in the Internet of Things (IOT), and the shift towards a new industrial paradigm based on cyber physical systems (CPS) are paving the way. If well applied at manufacturing processes, they will potentiate a new industrial revolution with enormous value, changing manufacturing nature forever. European industry needs to meet the increasing global consumer demand for greener, more customized and higher quality products through the necessary transition to a more efficient, flexible, responsive, digitalized and demand-driven industry with lower waste generation [3]. Manufacturing enterprises are pushed to take 'glocal' actions, i.e. thinking globally but acting and staying economically compatible with the local context [4]. The same can happen inside the factory, where enterprise level strategy needs to be accompanied by local action at the resources and devices. As an example, integrated systems for machining (e.g. CNC machines) are used worldwide, and organizational strategies need to be flexible to accommodate highly variable domains of application and consumer policy restrictions, configuring and allocating resources in-house depending of the product variant. Similar situation happens in more traditional SME-based environments such as furniture manufacturing, where product variability implies a great number of changes locally and is only possible with automation and reconfigurable production lines.

To answer these challenges the European Commission has identified the need for the advances in production architectures so that they become more responsive to dynamic market demands. This requires radical change of production topologies to achieve dynamic production re-configurability, scaling and resource optimization, fully exploiting the digital models of processes and products and to synchronization of the digital and physical world [5]. Based on these motivational factors, this paper proposes an architecture to support responsive production in manufacturing companies aiming to contribute for reindustrialization of manufacturing. Promoting the convergence of the physical and the digital worlds through CPS and IoT technologies, to accommodate more customized and higher quality products, the approach will also contribute to build trust in European companies and reinforce their position worldwide.

Recently, the term "Industry 4.0" has invaded all conversations about the future of industrial production. What started as a national initiative in Germany, rapidly evolved to a much more extended concept that is being used to identify what it is seen as the next industrial revolution [6]. In an initiative launched in April 2016, the European Commission recognizes the importance of promoting measures to support the development of a digitized European industry aiming to ensure that Europe is ready for the emerging challenges of digital products and services. Moreover, similar approaches are being followed outside EU (e.g. China has launched "Made in China 2025", United States created the "Smart Manufacturing Leadership Coalition" (SMLC) initiative, etc.).

The main goal of all these initiatives is to achieve the intelligent factory characterized by adaptability, resource efficiency, and ergonomics, as well as the integration of customers and business partners in business and value processes [7]. To achieve this challenging objective companies must cope with the increasingly stricter requirements in terms of flexibility, while maintaining their production capacity [8].

Currently, industrial companies are pushed to take 'glocal' actions, i.e. thinking globally but acting and 
staying economically compatible with the local context [9]. The same can happen inside the factory, where enterprise level strategy needs to be accompanied by local action at the resources and devices level. As an example, integrated systems for machining (e.g. CNC machines) are used worldwide, and organizational strategies need to be flexible to accommodate highly variable domains of application and consumer policy restrictions, configuring and allocating resources in-house depending of the product variant.

Manufacturing is typically associated to the transformation of raw material and assemblage of components into final products that fit the needs of many and can be sold worldwide. As a consequence, research and development (R\&D) in this domain has targeted the acceleration and mass-replication of more or less static production processes, construction of production machinery and the development of software to control such systems. However, the last decade has demonstrated clear signs that industry cannot proceed with "business as usual' practices. As identified by the European Commission's Future Internet Enterprise Systems cluster (FInES) roadmap in 2012, a change of paradigm is required to maintain and improve the current standard of life [10].

Mass replication, although still an important part of production, tends to lose space for customised products tailored to fit consumer needs and demands [9]. Also, as production stages and technologies have become more mobile, a single final manufactured good is nowadays often processed in different companies and countries, crossing several information systems (IS) with sequential tasks in the value chain. Therefore, the survival of enterprises in the near and long term future will depend on their ability to see their own role within the physical and social environment and to become flexible to changes in paradigm that can give them a competitive advantage.

The advances in digital automation can contribute significantly to help unleashing their potential to respond to these challenges [2]. Indeed, the explosion in the Internet of Things (IoT), and the shift towards a new industrial paradigm based on cyber physical systems (CPS) are paving the way.

In a Smart Factory (SF), everything is connected [11]. Production machines, humans, products, transport options and IT tools communicate with each other and

are organized with the objective of improving overall production, not only within the physical boundaries of the company but also beyond them. One of its key characteristics is the ability to decentralize control and decision as it facilitates modifications in the production process contributing to meet the increasing demand for mass customization.

This paper starts by identifying opportunities, challenges and main characteristics of Industry 4.0 followed by an analysis of the main barriers to its implementation. Then, related work is presented together with the highlights and the challenges that are to be addressed by the proposed architecture. The objectives to be achieved and the concept to support their achievement are also presented as well as the proposed architecture detailing the different modules that are being proposed. Finally, some conclusions are drawn and some future developments are discussed.

\section{Industry 4.0: Opportunities, Challenges and Main Characteristics}

When discussing how companies should be addressing the opportunities provided by Industry 4.0 it becomes obvious that some of them are still waiting for more clear advantages in joining the new paradigm. On the other hand, the examples of companies that are modernizing themselves keeps growing. This difference in attitude can be critical for the success, in the middle to long term, of companies that are not accompanying the trend.

Despite their position towards Industry 4.0 companies identify a set of opportunities regarding its adoption [6], namely:

- Increased competiveness: digitalization of industry will increase their competitiveness as it will impact both local and global value chains

- Easier adaptation to market changes-from "push into the market" to "pull from the consumer": the immense potential of industry 4.0 will facilitate the integration of customers needs and preferences into the development of new products and adaptation of production processes

- Risk and fault reduction: data integration and data analysis contribute for improved monitoring and thus reduce down times and faults. Cyber security will also be reinforced reducing hackerism risks

- Skilled workers and IT: investments on the education of workers as well as in appropriate infrastructure, although mandatory in most cases, are also seen as an opportunity for improving performance

- Use of currently growing technologies: smart sensors, 3D printing, etc., are seen as the key for accelerating the transformation for industry 4.0 by enabling rapid testing, prototyping and production adaptation.

It is possible to analyze the identified set of opportunities and to correlate them with some of the most promising technological developments that are considered the biggest contributors for making Industry 4.0 a reality. Concepts such as CPPS (Cyber-Physical Production Systems), and IloT (Industrial Internet of Things) have emerged and represent challenges that need to be tackled to answer the requirements of a continuously changing environment.

With roots on CPS, CPPS are systems of collaborating and autonomous across all levels of production, from processes through machines up to production and logistics networks [12]. They are capable of accessing, providing and using production data from real world at real-time. Aspects such as sovereignty, 
collaboration, optimization and responsiveness need to be especially addressed by CPPS. In addition to that, simulation, sensor networks, big data and security issues represent an important part to deal with challenge of CPPS implementation.

The recent advances on smart sensors, wireless networks and embedded systems, together with the consistent decrease of technology costs have contributed for the rapid development of industrially oriented IoT. Thus, IloT: the successful development of CPPS. Making use of technologies such as data acquisition and data integration, \&apabilities to capture and fuse information from various sensors/objects and cloud-based data centers, Ilo $\frac{f}{4}$ facilitates the adjustment of production parameters, opening new perspectives in easy reconfiguration of production lines, effective detection of failures, autonomous maintenance triggering and prompt reaction to unexpected changes in production. Although the possibilities for their application are immense there are still some technological issues that need to be addressed to ensure the full implementation of IloT (e.g. semantic integration and analysis for which additional developments on standards and protocols are needed).

CPPS together with IIoT enable the creation of a smart network of machines, ICT systems, smart products and people across the entire value chain and the full product life cycle. Interfacing with other infrastructures is also a reality enabling access to information coming from other smart platforms (e.g. smart logistics).

One key challenge is the introduction of the consumer perspective in the production process with the trend on customization growing every day. Manufacturing, especially in western countries, is no longer based on mass production but on mass customization in a "lot size 1" approach. Thus, links with social media networks are fundamental to access consumer expectations and desires.

To answer to the identified challenges and needs Industry 4.0 is composed by four main approaches that demonstrate its enormous potential for change (see Fig. 1):

- Vertical integration: responsible by the vision about high flexibility on pro duction towards full customization ("lot size 1") by fully integration of the internal value chain of the company.

- Horizontal integration: enables the inclusion of worldwide value network, and allows to work both on the processes as well on the systems till delivery of product to the customer.

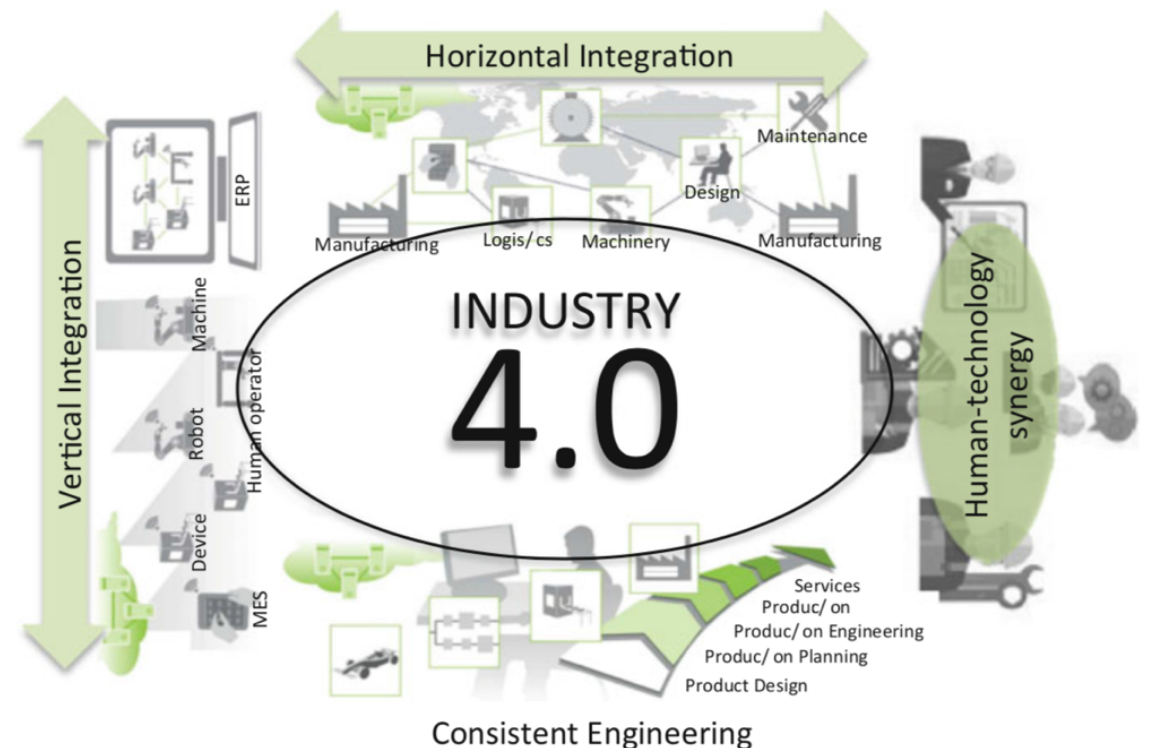

Fig. 1 Main characteristics of Industry 4.0 (adapted from [13])

- Consistent engineering: complete systems engineering, through production digitalization, from product design to product distribution, disposal and aftersales services.

- Human-technology synergy: promoting new skills and competences from the workforce, adapting working conditions (more attractive and productive) and safeguarding jobs.

\section{Barriers for Industry Digitalization}

All the aforementioned aspects can only be succeeded if supported by the developments on the areas previously mentioned. But, on the other hand, technological developments must be combined with social sciences and humanities in order to achieve human-technology synergy.

In fact, companies recognize that having the right people in place is critical for leveraging technological gain, and to accomplish the goals of smart manufacturing. The current perception about the so-called "skills gap" is that it will continuing growing as the percentage of new jobs needing highly skilled workers keeps increasing [11].

In addition to this, currently there is still a notion of manufacturing jobs as being less important in society, with lower incomes and poorly recognized. Many companies are facing huge difficulties in attracting talented resources to work with them as they are still very influenced by these views and companies need to work on 
their message to attract talents for industry [14].

Despite advanced digitization, horizontal integration, with suppliers, customers and other value chain partners, is progressing a slower than the vertical one [15]. Although the potential of greater horizontal integration is broadly recognized (e.g. offers the prospect of coordination of orders, materials flow and production data, with all companies along the value chain being able to add their own value-adding steps) there are still barriers that need to me removed to achieve it. These barriers are not only technological ones but also related with confidence and trust.

The World Economic Forum published the results of a 2014 [16] survey on Industrial Internet in which a set of barriers were identified by companies (see Fig. 2). The results demonstrated that almost two-thirds of the two major issues are related with security and interoperability. Other significant barriers cited include the lack of clearly defined return on investment (ROI), legacy equipment and technology immaturity.

Thus, in the latest years, interoperability and standards has been one of the areas capturing major attention from public and private institutions. In 2008, European Union launched Public-Private Partnership (PPP) for Factories of the Future (FoF). The FoF work program for 2018-2020 expects to mobilize more than €50bn of public and private investment with great focus on the development of standards for: 5G, Cloud Computing, Internet of Things, Data technologies and Cybersecurity.

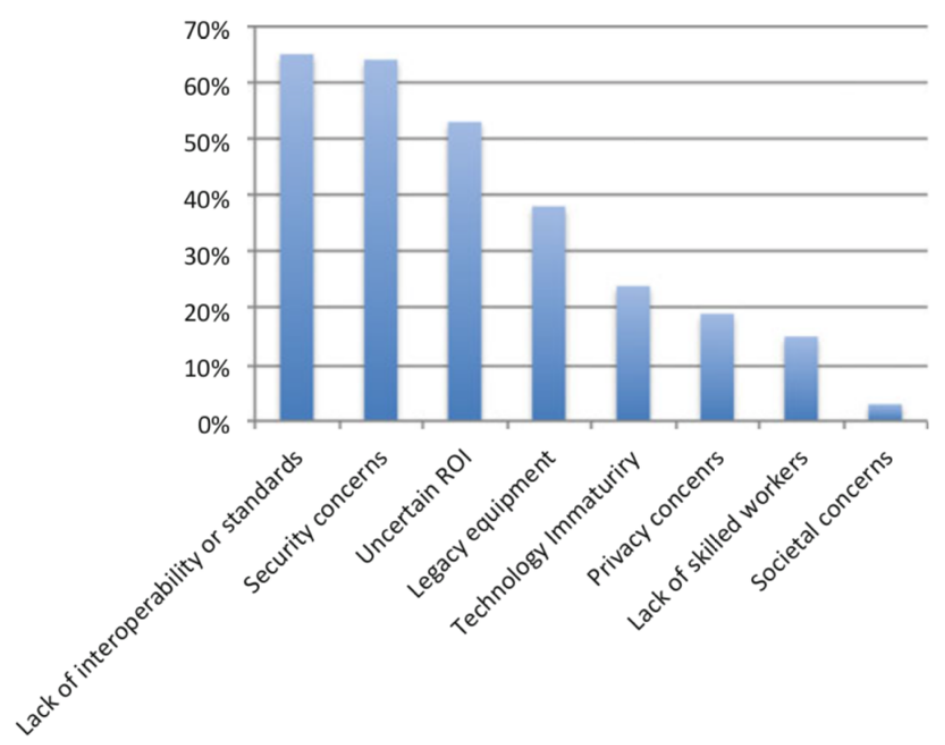

Fig. 2 Key barriers for industrial digitization

Interoperability is an essential problem of sharing information and exchanging services. It goes far beyond the simple technical problems of computer hardware and software, but encompasses the broad but precise identification of barriers not only concerning data and service but also process and business as well [17]. In fact, difficulties are observed when actors from various fields of expertise or with different types of resources are forced to exchange information [18, 19]. These difficulties arise at two levels:

- The difficulties to exchange data: observed when an actor does not have the proper tools to send or receive data. This is also observed when an actor is facing problems in accessing the content of the data files after receiving them.

- Difficulties in understanding the information exchanged: once the data exchanged, it must be ensured that the actors have a mutual understanding of the data. In fact, the diversity of actors and their areas of expertise, as well as differences in language and models complicate the uniqueness of meaning and understanding.

In what regards interoperability, traditional integration and interoperability services are often inflexible and difficult to adapt to meet dynamic requirements. Most development is either relying on international accepted standards for data exchange,

e.g. STEP, EDI/EDIFACT, ebXML, UBL, or is implemented on a peer-to-peer basis [20-22]. Architectures on integration and interoperability [23], modeling frameworks and tools, as well as methodological [24-26] are available but the real challenge resides in applying them to streamline data integration and interoperability while sustaining collaboration throughout market adaptation and innovation. This sustainability convenes the needs of the present without compromising the ability of future changes, meeting new system requirements [27]. Integration and interoperability is acknowledged with many researchers working in related domains, such as the digital and sensing enterprise [28], smart networks [29], or digital business innovation and big data [30]. In many cases, model driven and knowledge-based technology is being promoted [31], however they are rarely applied together and there is little concern on the company network sustainability, currently addressing interoperability only at the network design time. Jardim-Goncalves et al. [32] define sustainable interoperability as the development of novel strategies, methods and tools to maintain and sustain the 
interoperability of enterprise systems in networked environments as they inevitably evolve with their environments. These developments are fundamental to establish and maintain interoperability within the company (intra-interoperability) and also in the value

chain (extra-interoperability).

Additional work is also needed to develop widely accepted methods for privacy and security. One of the technologies that is positioning as being a strong possibility to deal with these issues is blockchain technology. It offers a way of recording transactions or any digital interaction in a way that is designed to be secure, transparent, highly resistant to outages, auditable, and efficient [33]. Its potential results from the following characteristics:

- Reliability and availability: in a network of participants, in case of node failure, the others will continue to operate, maintaining the information's availability and reliability.

- Transparency: transactions are visible to network participants, increasing auditability and trust.

- Immutability: changes are almost impossible to be made without being detected, increasing confidence in the information and reducing fraud opportunities.

- Irrevocability: transactions can be made irrevocable, increasing the accuracy of records and simplifying back-office processes.

- Digitalization: as almost any document or asset can be expressed in code, applications are endless.

Also, the development of mechanisms to support collaboration and information flow are also a key aspect for full horizontal integration. Nonetheless, to get there, companies have to get their vertical integration done first, starting at the heart of their production processes.

\section{Related Work and Proposed Novelties}

\subsection{CPS Production Architectures for Manufacturing}

Higher availability and affordability of sensors, data acquisition systems and computer networks as well as the competitive nature of the industrial sector have lead more companies to implement these technologies in their manufacturing processes and products. Today, an increasing number of industrial companies are introducing Internet of Things (IoT) and Cyber-Physical Systems (CPS) concepts starting with embedding sensors in manufacturing equipment or tagging products with RFID tags. Consequently, the growing use of sensors and networked machines has resulted in the continuous generation of high volume data that is known as Big Data [34]. In such an environment, CPS can be further developed for managing Big Data and leveraging the interconnectivity of machines to reach the goal of intelligent, resilient and self-adaptable machines [35]. Furthermore by integrating CPS with production, logistics and services in the current industrial practices, it would transform today's factories with significant economic potential [36]. An example of the potential benefits of transforming data coming from these devices into decisions is using embedded sensors in manufacturing equipment to predict equipment wear or diagnose possible faults with a reduction of maintenance costs by nearly 40\% [37]. Cyber-Physical Systems (CPS) is a transformative technology for managing interconnected systems between its physical assets and computational capabilities [38]. Since CPS is in the initial stage of development, it is essential to clearly define the structure and methodology of CPS as guidelines for its implementation in industry. In this sense, new CPS architectures are demanded so that they provide advanced connectivity that ensures real-time data acquisition from the physical world and information feedback from the cyber space; and intelligent data management, analytics and computational capability that constructs the cyber space [38]. An example is the proposed CPS 5C-level architecture [39] where Smartconnection, Data-To-information conversion, Cyber, Cognition and Configuration levels are associated to applications and techniques.

CPS architectures must take into account modularity and scalability issues, e.g. in case of a machine manufacturer a modular approach consist of component level, machine level, fleet level and enterprise level [40]. The architecture proposed by the authors will support the virtualization and synchronization of data coming from real world assets belonging to the whole supply chain where an industrial company is involved. Decentralization, modularity and scalability are key characteristics associated to this architecture in order to enhance the efficiency of production processes inside and outside of factories allowing the introduction of a more personalized and diversified product portfolio at competitive costs.

\subsection{Smart Factory and Factory Virtualization}

Smart Factory (SF) is a Factory that context-aware assists people and machines in execution of their tasks [41]. Mark Weiser [42] has coined the term ubiquitous computing for this new world. His vision as regards smart environments involves a physical world, closely and invisibly interwoven with sensors, actuators, displays and computer elements, which are seamlessly embedded into daily life objects and connected with each other by a network. Mark Weiser's approach of smart environments is transferred to manufacturing issues [41]. After the development of digital and virtual factories, the next step is the fusion of physical and digital/virtual world [43] under a so-called SF. The SF concept enables the real-time collection, distribution and 
access of manufacturing relevant information anytime and anywhere. Systems working in background accomplish their tasks based on information coming from physical and virtual world. SF represents a realtime, context-sensitive manufacturing environment that can handle turbulences in production using decentralized information and communication structures for an optimum management of production processes [41]. SF products, resources and processes are characterized by cyber-physical systems where materials are moved efficiently across the factory floor. This provides significant real-time quality, time, resource, and cost advantages in comparison with the traditional production systems. Sensing components such as actuators and sensors within the industrial set-up are expected to become "smart" as they are, increasingly, becoming selfsufficient with integrated computing abilities and low power consumption. SF will involve consolidation of existing solutions based on a holistic integration of field devices and technologies, including context-aware applications, federation platform, sensor fusion, status recognition, embedded systems, calm-systems (hardware), communication technologies (wireless), auto ID technologies, positioning technologies, and assistance of people and machines [41]. This integration is being driven by the need for seamless exchange of business intelligence to enhance the efficiency by the optimization of resource planning, scheduling, and controlling in real time [44]. Industrial automation platforms are experiencing a paradigm shift. New technologies and production strategies are enabling a synchronization of the digital and real world, providing real-time access to sensorial information, as well as giving technological infrastructures advanced networking and processing capabilities to actively cooperate and form a sort of 'nervous system' within the factory [45, 46]. Enterprise resources (e.g. assets in the form of materials, devices, people, etc.) can be transformed or consumed to produce such benefit. Yet, the development of applications that exploit knowledge from such heterogeneous resources will require a clear understating of all relations and inter-dependencies. Factory resources virtualization exposes an abstraction layer that removes inherent complexity and softens the innercompany operations, creating the conditions to improve agility, responsiveness, and decentralized decisionmaking [47]. Either by applying simple resource virtualization or mashup, factory virtualization allows to abstract, model and simulate the full automation pyramid, uniquely identifying and virtually representing the real physical entities (e.g. specific sensor) or some aggregation of them (e.g. combined knowledge) [48].

The architecture proposed handles major smart factory aspect through a total virtualization of the manufacturing production pyramid and by offering the capability of designing flexible production processes. Moreover, it will contribute to achieve the full virtualization process (i.e. total virtualization of the traditional automation pyramid from sensor-control to enterprise-level and/or methods and models for the synchronization of the digital and real world) and optimize the knowledge extraction for a comprehensive reasoning, visualization of factory reconfiguration and decentralized decision.

\subsection{Situational Awareness and Contextualization in Manufacturing}

Endsley [49] defines Situational Awareness (SA) as the perception of the elements in the environment within a volume of time and space, the comprehension of their meaning and a projection of their status in the near future. Three main theoretical approaches dominate the research of SA [50]: the information processing approach, the activity approach, and the ecological approach. The first one has been best represented by Endsley's [51] information processing-based three-level model, describing SA as a product comprising three hierarchical levels: Level 1, the perception of task relevant elements in the environment; Level 2, the comprehension of their meaning in relation to task goals; and Level 3, the projection of their future states. The activity theoretic approach presents SA as one of many components of reflective-orientational activity [52]. The model of the perceptual cycle presents SA as a dynamic interaction between humans and their environment. Proponents of this approach suggest that it is the context of the interaction that defines the SA [53]. Context simplifies and enriches human-human interaction. However, enhancing human-computer interaction through the use of contextualization remains a difficult task. Applications in pervasive and mobile environments need to be context-aware so that they can adapt themselves to rapidly changing situations [54]. Also, contextualization can represent a radical improvement in knowledge enrichment [55]. Industrial applications can be found in [56].

The architecture is based on the optimization of the knowledge extraction for the factory virtualization taking into account the physical and social context. Evolving from a context-specific and objective-oriented Situational Awareness (SA) to a shared SA, it enables the knowledge and understanding common to all the components involved in a situation to support an effective, collective response. SA will allow the generation of novel services, resource sharing and service quality development. By enhancing and promoting the SA capabilities, it will contribute to the factory virtualization process achieving much greater agility to more quickly meet changing business needs and an advanced and improved decentralized decision process.

\subsection{Decentralized Decision-Making}

Spatial Integration can be achieved in a centralized or decentralized way. In a centralized decision-making $(C D M)$ process, a single, decisional center (DC) is acquainted with all the system information. The central node is in charge of the system planning and owns the power to manage the operations performed by all the network nodes. The central node performs the decision-making in terms of optimizing the objectives of the entire network. In the decentralized decision-making (DDM) models each individual independent network 
entity makes its own decisions, trying to optimize its own objectives. More than one decision-maker is identified. Depending on the collaboration degree, the nodes will take into account (to a lesser or larger extent) the decisions of other nodes. In a DDM Collaborative mechanisms are needed to coordinate node's decisions and exchange the information [57, 58]. In a DDM model each independent entity, or DC, has its own objective function, which is subject to its constraints. In addition, the decision variables for each entity are often influenced by other entities' decisions, and the flows between levels [59].

To manage interdependent relationships of DDM, it is necessary to define mechanisms that are capable of coordinating the decisions made by the different nodes, as well as the information they exchange. These coordination mechanisms can be found in pre-agreed business rules, and assessment and comparison of alternatives using performance measurement techniques [60-63]. Information is a key aspect for decisionmaking. The structure of the information systems (IS) is usually supported by legacy software such as Enterprise Resource Planning (ERP) or other centralized software. First challenge is to synchronize the information stored in the ERP and the information managed in the Manufacturing System and second is to achieve a real-time updating of the information regarding unforeseen events.

System Theory [64] states that "an organization reacts to conflict by using analytical processes or bargaining processes". In this way, the recommendation [65] is that the problem solving process of conflict resolution is to identify a solution that satisfies the shared criteria building a decisional structure in order to decentralize the decision-making, taking in account the coherence of the objectives between the levels of decision.

This approach enables the classification of decision considering the time frame associated to the decision process (strategic, tactical, operational, real time) and will provide the criteria to decentralize the decision and facilitate the reactivity facing unpredicted events.

In the context of multi-stage Supply Chains (SC), when focusing on a certain decision-making temporal level it is usual to connect the decisions of a specific SC part with the decisions of the rest of the SC parts, especially with those that are immediately upstream or downstream. This is similar when the focus is in the factory at different levels of the automation pyramid.

Value chains are distributed and dependent on complex information and material flows requiring new approaches to reduce the complexity of manufacturing management systems. They need ubiquitous tools supporting collaboration among value chain partners and providing advanced algorithms to achieve holistic global and local optimization of manufacturing assets and to respond faster and more efficiently to unforeseen changes.

The way manufacturing and service industries manage their businesses is changing due to the emerging new competitive environments. According to [66] The enterprises' success in the new dynamic environments is associated to the improved competencies in terms of new business models, strategies, governance principles, processes and technological capabilities of manufacturing enterprises of 2020. Moreover, especially for SMEs, the participation in collaborative networks is also a key issue for any enterprise that is willing to achieve differentiated and competitive strengths. In the light of this, establishing collaborative relationships becomes an important issue to deal with customer needs, through sharing competencies and resources.

Collaborative Networks consist of a variety of heterogeneous autonomous entities, geographically distributed, in which participants collaborate to achieve a common goal and base their interactions through computer networks. SMEs are characterized by limited capabilities and resources therefore, in order to overcome possible barriers that can appear when establishing collaboration, joint efforts must be performed to achieve the desired collaborative scenarios. When establishing collaboration, networked partners share information, resources and responsibilities to jointly plan, implement, and evaluate a program of activities to reach a common goal and therefore jointly generate value. Thus, establish collaborative relationships imply sharing risks, resources, responsibilities, losses, rewards and trust.

The last decades show a clear trend in business: away from big comprehensive trusts which can cover all stages of a value creation chain, and away from long-standing, well-established and stable supply chains [67]. Most of the companies are moving their focus on their core business competencies and enter into flexible alliances for co-value creation and production. This requires flexible business process integration strategy and interoperable models.

Recent works in interoperability have provided promising results and have been partly responsible for initial commercial products and service offerings and operational deployed applications as discussed in [68, 69]. Collaborative systems need to be agile enough to address the changing needs in manufacturing processes. Agile and resilient enterprises have to cope with the complexity of information presented in many interconnected dimensions, and continuously adapt and re-organize themselves [70]. Representing the enterprise as a static system neglects issues raised by the dynamics of today's business [71].

To achieve this level of collaboration companies must be capable of interoperate. Enterprises today face many challenges related to the lack of interoperability, as most of their Information and Communication Technology (ICT) solutions are often inflexible and difficult to adapt to meet the requirements of those changing enterprises [72].

Assuming that the problems regarding interoperability are solved and that all the network participants are able to communicate and understand each other, a new range of collaboration opportunities is open. Among these, the possibility to implement mechanism for decentralized decision-making. In this context we are 
basically looking for decision that are strategic (i.e. related to network's mission and objectives) and/or tactical (decisions that will contribute to the longevity, profitability, and continued improvement of all areas of operation).

As we are focusing on decisions that are made within a network of stakeholders, procedures that enable decentralized decision-making are sought. In these cases the decision-making methods are not the central part of the problem. Instead, the most important aspects are related with the establishment of the decision process. For this

[73] proposes a six-step approach to facilitate the collaborative decision-making:

1. Ensure leadership and commitment: despite the collaborative nature of the process, the existence of facilitator that owns the process is defended to ensure the success;

2. Frame the problem: specifying known policies, givens, and constraints; identifying problem areas and uncertainties; and defining assumptions and details that are follow-on parts of the decision

3. Develop evaluation models and formulate alternatives: achieving consensus about how success will be measured is fundamental. Alternatives must be developed based on the network vision, framing of the problem and understanding of the issues requiring consideration and alternatives that overlap or are not independent must be identified.

4. Collect meaningful, reliable data: all decision processes require colleting the right information (i.e. the one that is critical for the decision to be made) in an appropriate amount (excluding information that can contribute to turn the decision process messy). The use of decision analysis tools (e.g. Nominal Group Technique-NTG [74]) can be helpful for identifying what information is meaningful to the process and how it should be collected. Evaluate alternatives and make decision: Evaluate identified alternatives and select the one that best fits the criteria. Several decision making tools can be used in this step from a simple cost-benefit analysis to multi criteria decision methods (e.g. Analytical Hierarchy Process-AHP [75])

5. Develop an implementation plan: success of the process depends on how decisions are implemented. The definition of an implementation plan allows to consider barriers, performance interventions, and project management issues. To support the development action plans and decision tree diagrams can be used.

Collaborative decision-making is a complex task especially in what regards the human factor that is involved. Thus, the criticality along the process resides in the steps, which involve interaction among participants and to reach a consensus. This is the reason why Step 1: Ensure leadership and commitment is the most important. The selection of the facilitator can also be made following different strategies. When focusing on value chain networks the facilitator this selection can be made using two different strategies:

- Select an impartial and trustworthy entity, external to the network;

- Within the network, select a different facilitator depending on aim of decision process.

In the second case, a set of rules must be defined at network setup to make this selection clear and accepted by all involved stakeholders. Also, if new partners join the network the set of rules must be communicated and accepted.

The architecture here presented establishes the relation between CPS and the 'glocal' Decision/Information Structure allowing modular virtualization and modeling of the factory automation pyramid. This approach will enable the classification of decision considering the time frame associated to the decision process (strategic, tactical, operational, real-time) and will provide the criteria to decentralize the decision and facilitate the reactivity facing unpredicted events.

\section{Vision for Smart Factory Responsive Production}

\subsection{Objectives}

The main objective of the proposed approach is to support the design and reconfiguration of manufacturing plants so that they can easily respond to new demands. These demands can be external (e.g. market demands) or internal (e.g. energy efficiency demands). To achieve this objective the approach proposes a decentralized modular production architecture to support the design and reconfiguration of the manufacturing plant.

The proposed architecture targets at providing support for the following functionalities: (i) total virtualization of the factory automation pyramid enabling remote control and (re)programing of production lines contributing for a reduction on the number of on-site changes and time to start-up, (ii) reconfiguration/adaptation/ evolution of factories to facilitate reaction to uncertainties/disruptions, (iii) modularization of the production process and product life-cycle to reach mass-personalized product port-folio, and (iv) decentralization of decision-making, allowing responsiveness improvement. 


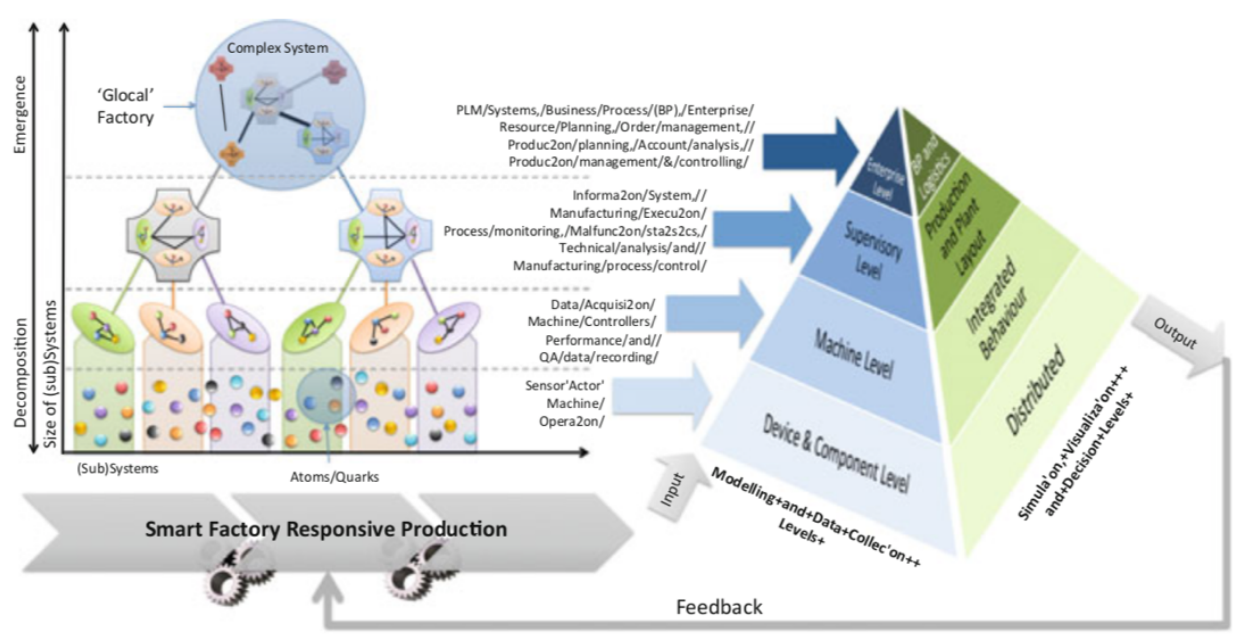

Fig. 3 Vision for smart factory responsive production

The architecture is used to develop the smart factory responsive production platform (Fig. 3). It acts as the operating system of the smart factory, and will support the entire production process and product lifecycle, contributing for a more personalized, diversified and mass-produced product portfolio and for rapid, flexible and responsive reaction to market changes. The baseline idea is that the virtualization of the entire automation pyramid will enable synchronization of the digital and real world.

Thus, starting from the virtualization of the automation pyramid, and using a modular approach to decompose all the production processes, reconfiguration and/ or readjustments will be facilitated taking advantage of a complex systems perspective, enabling factory 'glocality'. The development of modular blocks, modeling the production steps, which can be automatically reconfigured and/or reorganized at the different levels, enables decentralized process co-simulation and optimization (e.g. testing several combinations) while keeping costs and risks at a low level.

\subsection{Concept}

Manufacturing is typically associated to the transformation of raw material and assemblage of components into final products that fit the needs of many and can be sold worldwide. As a consequence, research and development (R\&D) in this domain has targeted the acceleration and mass-replication of more or less static production processes, construction of production machinery and the development of software to control such systems. Mass replication, although still an important part of production, tends to lose space for customized products tailored to fit consumer needs and demands. Also, as production stages and technologies have become more mobile, a single final manufactured good is nowadays often processed in different companies and countries, crossing several information systems (IS) with sequential tasks in the value chain. Therefore, the survival of enterprises in the near and long term future will depend on their ability to see their own role within the physical and social environment and to become flexible to changes in paradigm that can give them a competitive advantage. Together with flexibility and mobility, complexity has also risen, representing an immense opportunity for technologies such as Cyber Physical Systems (CPS), Internet of Things (loT) and data analytics. These technologies, when correctly used are capable of providing a huge impact on the factories daily operations. Supported by smart components delivering global and physical awareness to the business systems, they will enhance overall context awareness and the opportunity for better decisions. Complexity science theorizes simple causes for complex effects, with rules that determine how a set of agents behave and interact over time within their environment. It does not predict an outcome for every state, and uses feedback and learning algorithms to enable systems to adapt to its environment over time. In the domain of factory systems, the application of these rules to a large population leads to emergent behaviour that may emulate real-world phenomena. Figure 1, can be used to better explain the concept of the Smart Factory Responsive Production. Highlighting the link between emergent complexity and an enterprise organization, it is easy to observe that the automation pyramid can be directly associated to complexity theories and the 'Glocal' factory idea:

- The bottom-up perspective (emergence) enables to understand how simpler systems can be aggregated to provide more complex functions in the frame of the decomposition structure. The proposed architecture relies on this idea and seeks to collect information and act on systems as simple as possible, making use of the pyramid to take input data and knowledge directly from the lower level devices and components up-to the enterprise level where production planning can be reconfigured, products redesigned, etc. Depending on the level of decision required, the emergent flow might not reach the top of the pyramid, decentralizing control and increasing automation.

- The top-down perspective (decomposition) allows to define the global structure of the pyramid by 
introducing decentralization mechanisms and modularization that will be responsible for decreasing levels of complexity to a point where simulation, visualization and decision can be distributed and used to facilitate control and actuation on the real world.

The combined bottom-up and top-down perspectives, enables the resolution of problems, offering a structure of decomposition that discovers inputs from localized mechanisms (e.g. self-adaptation triggered by smart objects), instead of always starting the "responsive" process from the higher level of the automation pyramid. This will create a feedback loop into the manufacturing process that allows reconfiguring and reorganizing physical, human and computational resources in a better form to respond to new trends in masscustomization and re-shoring, as well as unforeseen problems in the daily operation. This concept is also tightly connected with the vision of Sensing Enterprise that was created to reconcile traditional non-native "Internet-friendly" organizations with the tremendous possibilities offered by the cyber worlds [37]. It envisions the enterprise as a smart complex entity capable of sensing and reacting to stimuli, by integrating decentralized intelligence, context awareness, dynamic configurability and sensorial technology into its decision-making process. The enterprise uses visualization and simulation techniques to anticipating future behaviour and taking decisions on multi-dimensional information captured through physical and virtual objects.

\section{Architecture to Support Responsive Production}

The proposed architecture for Smart Factory Responsive Production was developed taking into consideration aspects such as: decentralization, modularity, scalability and responsiveness. Figure 4 presents the developed architecture and the following sections describe the proposed set of building blocks and services.

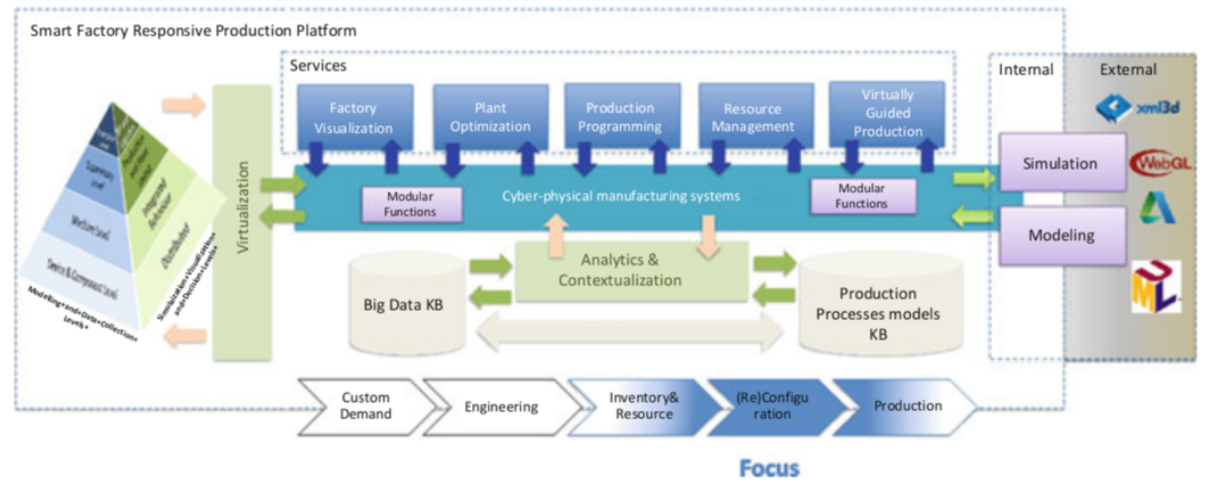

Fig. 4 Architecture for smart factory responsive production

\subsection{Modular Building Blocks}

- Virtualization: Responsible for providing bi-directional access to the different automation pyramid levels, including data collection, reading and writing functionalities. Also supports decentralized decision-making providing systematic decision mechanisms to deal with multi-level hierarchical systems enabling the rapid resolution of local problems.

- Analytics and Contextualization: Analyses and contextualizes the collected data enriching it and enabling anomalies detection, future evolution predictions, data interpretation and complex event detection.

- Cyber-physical manufacturing systems: Implements the modular functions needed to describe the different manufacturing systems available, together with the appropriate communication, decision and control mechanisms. All information from all related manufacturing systems is closely monitored and synchronized between the physical factory floor and the cyber computational space.

- Modeling and Simulation: Provides modeling and simulation functionalities, at both business and physical layers, and across the different levels of the automation pyramid. Whenever possible enables integration with external modeling and simulation tools making use of their capabilities.

- Knowledge bases: Namely "Big Data KB", which will gather and contextualize relevant knowledge for the virtualization process, and "Production Process Models KB", responsible for storing the selected production processes that were found to be relevant for the approach.

\subsection{Set of Services}

The set of Services assemble the intelligent and automated functions at the CPS layer. As the functions at the CPS layer of the architecture are modular, they can be combined in a number of different ways for the elaboration of further services. In addition to this, the approach envisages to that development should open for integration with other (external) systems as well as to allow different combinations of the building blocks to support the development of new services. The envisaged services provide:

- "Factory Visualization": enables users to access and view, in a digital and virtual interface, the factory and its resources, at a certain point in time. This functionality can become quite useful providing support to 
human decision, providing simple interaction to navigate layouts and correlate past, present and future resource configurations.

- "Plant Optimization": focused on the plant and production line layouts. Based on the needs of different products and customizations, plant layout configuration can be optimized for a certain time-frame.

- "Resource Management": exposes, through a simple interface, factory resources (Human, Physical and Computational). Using this service, and depending on their access rights, users (e.g. production managers) can perform activities such as: resource re-allocation within a certain space or time frame, material management, resource sharing within certain tasks, physical or computation resource reconfiguration, etc.

- "Production Programming": enables users to have an harmonized interface to quickly be able to reprogram machine controllers and smart objects in a way that they can behave in the desired form, and respond to the reconfigurations necessary.

- "Virtually guided production": changes to the planning, provisioning, resource allocation and production tools of the ongoing projects become difficult to manage. This service complements the automatic rearrangements with a guideline for management and workers, providing a step-by-step checklist for readjustments and changes to perform.

\section{Conclusions and Future Work}

Industry 4.0 represents a huge opportunity, as well as very demanding challenge, for companies. On the other hand, companies that choose to ignore it may be at stake and will for sure struggle in this new production approach. In this paper the authors start by contextualizing the potential that represents industrial digitalization and how technological advances can contribute for a new perspective on manufacturing production.

The architecture here proposed aims at combining virtualization, contextualization and decentralized decision-making to improve production responsiveness and promote plant adaptation. Moreover, the utilization of multiple technologies, such as IOT and CPS, is the key for the convergence of the physical and digital worlds contributing to achieve increased production quality (i.e. by reducing risks through testing combinations) and mass customization. From technological point of view, the access to multiple sources of information together with the processing of that information to generate new and improved knowledge (data analytics) is fundamental for the implementation of the proposed approach.

The developed work answers to specific needs and challenges that must be addressed to solve problems related with dynamic market changes, which are intimately connected with the design and reconfiguration of the manufacturing enterprise. Specifically, the proposed architecture, aims at providing a baseline for further developments in terms of supporting platforms that combine smart factory responsive production, combining virtualization, contextualization, modeling and simulation functionalities to enable self-adaptation to dynamic market demands.

Future work will be directly related with the implementation of the proposed architecture in real industrial scenarios in order to test its appropriateness.

Moreover, and in what regards validation, scenarios will focus in design and reconfiguration of the manufacturing enterprise to test the capacity of answer easily to dynamic market demands.

Acknowledgements The research leading to these results has received funding from the European Union H2020 project C2 NET (FoF-01-2014) nr 636909.

\section{References}

1. European Comm ss on: For a European Industra Rena ssance, Commun cat on from the Comm ss on to the European Par ament, the Counc, the European Econom c and Soc a Comm ttee and the Comm ttee of the Reg ons (2014)

2. Hartmann, B., Kng, W.P., Narayanan, S.: Dg ta manufacturng: the revo ut on $w$ be vrtua zed. McK nsey \& Company (2015)

3. European Forum for Manufacture: Drv ng Innovat on and Growth n European Manufactur ng (2015)

4. European Factor es of the Future Research Assoc at on (EFFRA): Factor es of the Future: Mu t-annua Roadmap for the Contractua PPP under the Hor zon 2020 (2013)

5. European Comm ss on: Hor zon 2020-Work Programme 2016-2017: 17. Cross-cutt ng Act v t es (2016)

6. Sch aepfer, R.C., Koch, M., Merkofer, P.: Industry 4.0 cha enges and so ut ons for the $\mathrm{dg}$ ta transformat on and use of exponent a techno og es. De o tte AG (2015)

7. 7 D: Industry 4.0. https://www.7 d.com/techno ogy/ ndustry-4-0/ (2016)

8. European Comm ss on: Hor zon 2020-Work Program 2016-2017-Cross-cutt ng Act v t es, 25 Ju y 2016

9. EFFRA: Factor es of the Future: Mu t-annua Roadmap for the Contractua PPP under the Hor zon 2020 (2013)

10. FInES Research Roadmap Task Force (2012)

11. Jac nto, J.: Smart manufacturng? Industry 4.0? What $\mathrm{s} t \mathrm{a}$ about? Sements Tota y Integrated Automat on, Automat on Wor d \& Des gn Wor d (2014)

12. Monostor, L.: Cyber-phys ca product on systems: roots, expectat ons and R\&D cha enges. Proced a CIRP 17, 9-13 (2014)

13. Ado phs, P.: RAMI 4.0—An arch tectura Mode for Industr e 4.0. P atform Industr e 4.0 (2015)

14. Co ns, M.: Why Amer ca has a shortage of sk ed workers. Industry Week (2015)

15. Forbes, J., Naujok, N., Ge ssbauer, R., Vedso, J., Schrauf, S.: Industry 4.0: bu d ng the d g ta enterpr se. PWC (2016)

16. Wor d Econom c Forum Industr a Internet Survey (2014) 
17. Chen, D., Vernadat, F.B.: Enterpr se nteroperab ty: a standard sat on v ew. Enterpr se Interand Intra-Organ zat ona Integrat on, Vo ume 108 of the ser es IFIP-The Internat ona Federat on for Informat on Process ng, pp. 273-282 (2003)

18. Yan, L., L , Z., Yuan, X.: Study on method-of-robust-mu t d sc p nary-des gnco aborat ve-dec s on for product des gn. Inf. Techno . J. 8(4), 441-452 (2009)

19. Ruz Dom nguez, G. A.: Caractér sat on de act v té de concept on co aborat ve à d stance: étude des effets de synchron sat on cogn t ve (2005)

20. Jung, J.J.: Reus ng onto ogy mapp ngs for query routng $\mathrm{n}$ semant c peer-to-peer env ronment. Inf. Sc. (2010). https://do .org/10.1016/j. ns.2010.04.018

21. Ranjan, R., Zhao, L., Wu, X., L u, A., Qu roz, A., Parashar, M.: Peer-to-Peer C oud Prov s on ng: Serv ce D scovery and Load-Ba anc ng. https://do .org/10.1007/978-1-84996-241-4_12

22. Agost nho, C., P nto, P., Jard m-gonca ves, R.: Dynam c adaptors to support mode -dr ven nteroperab ty and enhance sens ng enterpr se networks. In: 19th Wor d Congress of the Internat ona Federat on of Automat c Contro (IFAC 14), Cape Town, South Afr ca (2014)

23. Chen, D., Doume ngts, G., Vernadat, F.: Arch tectures for enterpr se ntegrat on and nteroperab ty: past, present and future. Comput. Ind. 59, 647-659 (2008). https://do .org/10. 1016/j.comp nd.2007.12.016

24. Ducq, Y., Chen, D., A x, T.: Pr nc p es of serv tzat on and defin t on of an arch tecture for mode dr ven serv ce system eng neer ng. In: 4th Internat ona IFIP Work ng Conference on Enterpr se Interoperab ty (IWEI 2012), Harb n, Ch na, 2012. https://do .org/10.1007/978-3-642-33068-17_12

25. E vesæter, B., Hahn, A., Berre, A., Nep e, T.: Towards an nteroperab ty framework for mode -dr ven deve opment of software systems. In: 1st Internat ona Conference on Interoperab ty Enterpr se Software and App cat ons. Spr nger. http://www.spr nger nk.com/ ndex/ L10NU4306N054T6G.pdf (2005)

26. OMG: MDA Gu de Vers on 1.0.1 (omg/2003-06-01), Object Management Group. http:// www.omg.org/cg b n/doc?omg/03-06-01.pdf (2003)

27. Agost nho, C., Ducq, Y., Zacharew cz, G., Sarra pa, J., Lampathak, F., Po er, R., Jard m-Gonca ves, R.: Towards a susta nabe nteroperab ty $\mathrm{n}$ networked enterpr se nformat on systems: trends of know edge and mode-drven techno ogy. Comput. Ind. (2015). https://do .org/10.1016/j.comp nd.2015.07.001

28. Santucc, G., Mart nez, C., V ad-câ c c, D.: The sens ng enterpr se. In: FInES Work. FIA 2012, Aa borg, Denmark. http://www.the nternetofth ngs.eu/s tes/defau t/fi es/\%5Buser-name $\% 5$ D/Sens ng-enterpr se.pdf (2012)

29. Sr ram, R.: Smart networked systems and soc et es: what w the future ook ke? In: IEEE IT Profess ona Conference (IT Pro). IEEE Computer Soc ety (2014)

30. Many ka, J., Chu, M., Brown, B., Bugh n, J., Dobbs, R., Roxburgh, C., et a .: B g data: the next front er for nnovat on, compet ton, and product $\mathrm{v}$ ty. ns ghts/bus ness techno ogy/b g data the next front er_for_nnovat on (2011)

31. Zacharew cz, G., D a o, S., Ducq, Y., Agost nho, C., Jard m-Gonca ves, R., Bazoun, H., Wang, Z., Doume ngts, G. Mode -based approaches for nteroperab ty of next generat on enterpr se nformat on systems: state of the art and future cha enges. Inf. Syst. e-Bus. Manag. (2016). https://do .org/10.1007/s10257-016-0317-8

32. Jard m-Gonca ves, R., Agost nho, C., Ste ger-Garcao, A.: A reference mode for susta nabe nteroperab ty $n$ networked enterpr ses: towards the foundat on of El sc ence base. Int.

J. Comput. Integr. Manuf. 25(10) (2012). (Speca Issue on Co aborat ve Manufacturng and Supp y Chans). https://do .org/10.1080/0951192x.2011.653831

33. Schatsky, D., Murask n, C.: B ockcha n s com ng to d srupt your ndustry. De o tte (2015)

34. Sh, J., Wan, J., Yan, H., Suo, H.: A survey of cyber-phys ca systems. In: Internat ona Conference on W re ess Commun cat ons and S gna Process ng, pp. 1-6 (2011)

35. Rajkumar, R.: Workshop report on foundat ons for nnovat on $\mathrm{n}$ cyber-phys ca systems. NIST. http://www.n st.gov/e /up oad/CPS-WorkshopReport-1-30-13-F na .pdf/ (2013)

36. Lee, J., Lap ra, E., Yang, S. Kao, H.-A.: Pred ct ve manufacturng system trends of next generat on product on systems. In: 11th IFAC Workshop on Inte gent Manufacturng Systems, vo. 11, ssue 1, pp. 150-156 (2013)

37. IDC: The dgta un verse of opportuntes: $r$ ch data and ncreas ng va ue of the nternet of th ngs. EMC Dgta Un verse. emc.com/co atera /ana yst-reports/ dc-d g ta -un verse-2014. pdf. (2014)

38. Bahet, R., G , H.: Cyber-phys ca systems. Impact Contro Techno . 1-6 (2011)

39. Lee, J., Bagher, B., Kao, H.-A.: A cyber phys ca systems arch tecture for Industry 4.0-based manufactur ng system. Manuf. Lett. 2015, 3, 18-23 (2014). https://do .org/10.1016/j.mfg et. 2014.12.001

40. Bagher, B., Lee, J.: Bg future for cyber-phys ca manufacturng systems. Desgn Word. http://www.des gnwor don ne.com/b g-future-for-cyber-phys ca -manufactur ng-systems/ (2015)

41. Lucke, D., Constant nescu, C., Westkämper, E.: Smart factory-a step towards the next generat on of manufactur ng. Manufactur ng Systems and Techno og es for the New Front er, pp. 115-118. Spr nger, London (2008)

42. We ser, M.: The Computer for the 21st Century. Sc ent fic Amer can, Spec a Issue on Commun cat ons. Comput. Netw. (1991)

43. Westkämper, E., Jendoub, L., E sse e, M., Ert, T.: Smart factory—br dg ng the gap between dg ta pann ng and rea ty. Manuf. Syst. 35(4), 307-314 (2006)

44. Goryachev, A., Kozhevn kov, S., Ko bova, E., Kuznetsov, O., S monova, E., Skobe ev, P., Tsarev, A., Shep ov, Y.: Smart factory: nte gent system for workshop resource a ocat on, schedu ng, opt $m$ zat on and contro $\mathrm{ng} n$ rea $\mathrm{tme}$. Adv. Mater. Res. 630, 508-513 (2012)

45. Agost nho, C., Marques-Lucena, C., Sesana, M., Fe c, A., F scher, K., Rubatt no, C., Sarra pa, J.: Osmos s process deve opment for nnovat ve product des gn and va dat on. 2015 ASME IMECE, Houston, USA (2015)

46. Ko, J., Lee, B., Lee, K., Hong, S.G., K m, N., Paek, J.: Sensor v rtua zat on modu e: v rtua z ng loT dev ces on mob e smartphones for effect ve sensor data management. Int. J. D strb. Sens. Netw. (2015). https://do .org/10.1155/2015/730762

47. Guo, T., Papa oannou, T.G., Aberer, K.: Effic ent ndexng and query process ng of mode - $v$ ew sensor data $n$ the c oud. J. B g Data Res. 1, 52-65 (2014)

48. Kumra, S., Sharma, L., Khanna, Y., Chattr, A.: Ana ys ng an ndustr a automat on pyram d and provd ng serv ce 
or ented arch tecture. Int. J. Eng. Trends Techno . 3(5), 586-594 (2012)

49. Ends ey, M.: Des gn and eva uat on for s tuat ona awareness enhancement. In: Proceed ngs of the Human Factors Soc ety 32nd Annua Meet ng. HFES, Santa Mon ca, pp. 97-10 (1988)

50. Stanton, N.A., Chambers, P.R., P ggott, J.: S tuat ona awareness and safety. Saf. Sc . 39(3), 189-204 (2001)

51. Ends ey, M.: Toward a theory of $\mathrm{s}$ tuat on awareness $\mathrm{n}$ dynam $\mathrm{c}$ systems. Hum. Factors (The Journa of the Human Factors and Ergonom cs Soc ety) 37, 32-64 (1995)

52. Bedny, G., Me ster, D.: Theory of act $v$ ty and $s$ tuat on awareness. Int. J. Cogn. Ergon. 3(1), 63-72 (1999)

53. Sm th, K., Hancock, P.A.: S tuat on awareness s adapt ve, externa y d rected consc ousness. Hum. Factors (The Journa of the Human Factors and Ergonom cs Soc ety) 37(1), 137-148 (1995)

54. Ranganathan, A., Campbe, R.H.: An nfrastructure for context-awareness based on first order og c. Pers. Ub qu t. Comput. 7(6), 353-364 (2003)

55. N ng, K., Scho ze, S., Marques, M., Campos, A, Neves-S va, R. O Su van, D.: A serv ce or ented p atform for context aware know edge enhanc ng. In: 5th IFAC Conference on Management and Contro of Product on and Log st cs (2010)

56. Marques, M., Suc c, B., Vuk, T.: Context-based dec s on support for susta nab e opt $m$ zat on of energy consumpt on. KES Trans. Susta n. Des. Manuf. 1(1), 899-910 (2014)

57. Schneewe ss, C.: D str buted dec s on mak ng n supp y cha n management. Int. J. Product. Econ. 84, 71-83 (2003)

58. A emany, M.M.E., A arcón, F., Lar o, F.C., Boj, J.J.: An app cat on to support the tempora and spat a d str buted decson-makng process $n$ supp y cha $n$ co aborat ve pann ng. Comput. Ind. 62(5), 519-540 (2011). https://do .org/10.1016/j.comp nd.2011.02.002

59. Hong, I.H., Ammons, J.C., Rea ff, M.J.: Centra zed versus decentra zed dec s on-mak ng for recyc ed mater a fows. Env ron. Sc. Techno . 42(4), 1172-1177 (2008)

60. P bern k, R., Sucky, E.: An approach to nter-doma n master pann ng n supp y cha ns. Int. J. Product. Econ. 108, 200-212 (2007). https://do .org/10.1016/j. jpe.2006.12.010

61. Lee, H., Whang, S.: Decentra zed mu t-eche on supp y cha ns: ncent ves and nformat on. Manag. Sc . 45(5), 633640 (1999)

62. Jung, H., Chen, F., Jeong, B.: Decentra zed supp y cha $n$ pann ng framework for th rd party og st cs partnersh $\mathrm{p}$. Comput. Ind. Eng. 55(2), 348-364 (2008). https://do .org/10.1016/j.c e. 2007.12.017

63. Wang, K.-J., Chen, M.-J.: Cooperat ve capacty $p$ ann ng and resource a ocat on by mutua outsourc ng us ng ant a gor thm $n$ a decentra zed supp y cha $n$. Expert Syst. App . 36(2), 2831-2842 (2009)

64. S mon, H.A.: The Sc ence of the Art fic a, 1st edn. MIT Press, Cambr dge, Mass, (1969). (3rd ed. n 1996, MIT Press)

65. Mesarov c, M.D., Masko, D., Takahara, Y.: Theory of Herarch ca Mut eve Systems. Academ c Press, New York and London (1970)

66. Camar nha-Matos, L.M., Afsarmanesh, H.J.: Co aborat ve networks: a new sc ent fic d sc p ne. J. Inte . Manuf. 16(4), 439-452 (2005)

67. Popp ewe , K., Stojanov c, N., Abecker, A., Aposto ou, D., Mentzas, G., Hard ng, J.: Support ng adapt ve enterpr se co aborat on through semant c know edge serv ces. In: Enterpr se Interoperab ty I: New Cha enges and Industra Approaches, pp. 381-393 (2008). http://do .org/10.1007/978-1-84800-221-0_30

68. Agost nho, C., Ducq, Y., Zacharew cz, G., Sarra pa, J., Lampathak, F., Jard m-Gonca ves, R., Po er, R.: Towards a susta nabe nteroperab ty $\mathrm{n}$ networked enterpr se nformat on systems: trends of know edge and mode-drven techno ogy. Accepted for Pub cat on at Computers n Industry. http://do .org/10.1016/j.comp nd.2015.07.001

69. Agost nho, C., Jard m-Gonça ves, R.: Sustanng nteroperab ty of networked qu d-sens ng enterpr ses: a comp ex systems perspect ve. Annu. Rev. Contro 39, 128-143 (2015). https:// do .org/10.1016/j.arcontro .2015.03.012

70. We chhart, G., Mo na, A., Chen, D., Wh tman, L. E., Vernadat, F.: Cha enges and current deve opments for sens ng, smart and susta nabe enterprse systems. Computers $n$ Industry (2015). http://do .org/10.1016/j.comp nd.2015.07.002

71. We chhart, G.: Support ng Interoperab ty for Chaot c and Comp ex Adapt ve Enterpr se Systems. On the Move to Mean ngfu Internet Systems: OTM 2013 Workshops. Confederated Internat ona Workshops: OTM Academy, OTM Industry Case Stud es Program, ACM, EI2N, ISDE, META4eS, ORM, SeDeS, SINCOM, SMS, and SOMOCO 2013. Proceed ngs: LNCS 8186, 86-92. (2013). http://do .org/10.1007/978-3-642-41033-8_14

72. Truex, D.P., Baskerv e, R., Ken, H.: Growng systems n emergent organ zat ons. Mag. Commun. ACM CACM Homepage Arch. 42(8), 117-123 (1999)

73. We berg, S.: Fac tat ng co aborat ve decson-makng $\mathrm{n} s \mathrm{x}$ steps. Internat ona Assoc at on of Fac tators Annua Meet ng, pp. 14-15 (1999)

74. De becq, A.L., VandeVen, A.H.: A group process mode for prob em dent ficat on and program pann ng. J. App. Behav. Sc . 7, 466-492 (1971). https://do .org/10.1177/ 002188637100700404

75. Saaty, T.L.: The Ana yt c H erarchy Process. McGraw-H , New York, USA (1980) 